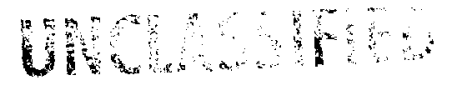

33679000614455

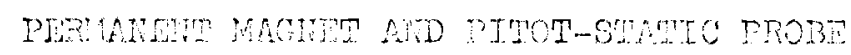

FTORETHE TOR LIOUAD COTIS:

D. L. Lessor

13. H. Duane

Theoretical and reutron Physic: Bection

Physics Penench Deintiont

Physics and Dnoincering Division

$l^{*} a y, 1069$

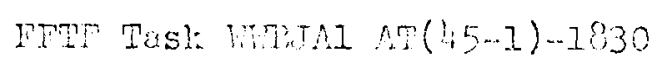

BNWL-1123 DRI

Draft Issue \#]

2

$5-69$ 
INFORMATION CONCERNING USH OF THIS REPORT

\section{PATTIT STITLS}

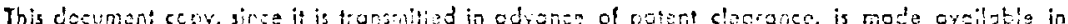

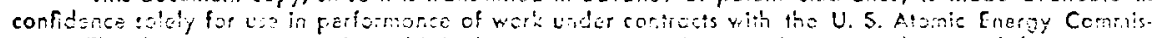

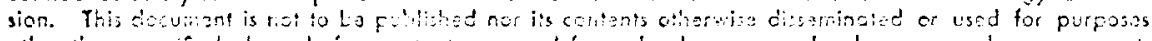

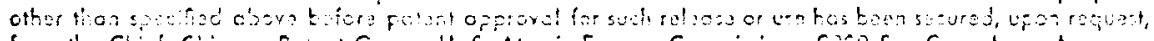

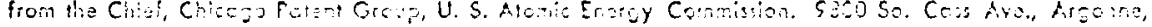
inincis.

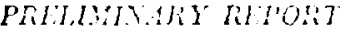

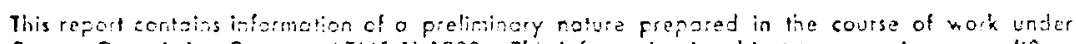

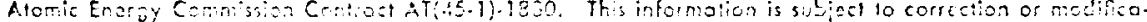

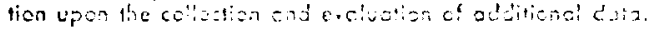

LEG.1L . LOTCK

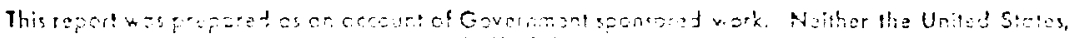

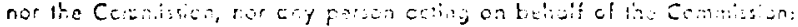

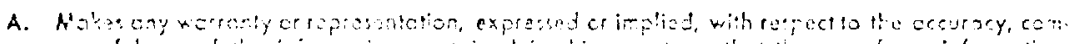

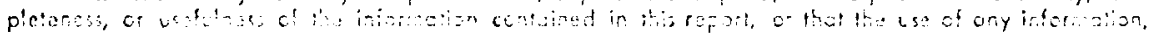

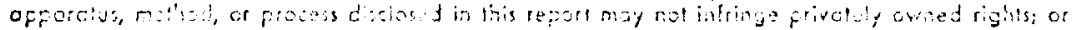

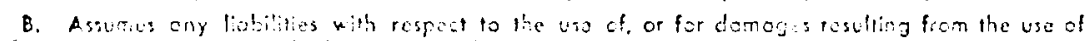
ony informeticn, opates, rathed, or pecess disclesed in this report.

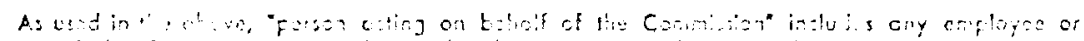

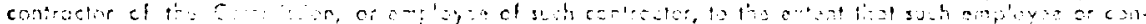

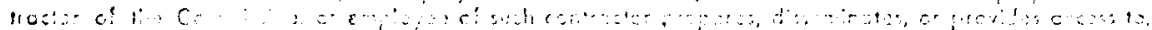

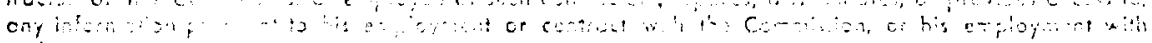
$\sec 5:-2,1$,

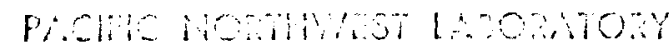

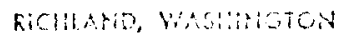

opercilad by 


\section{ABS:}

A pemenent manet probe mo to mo a pitot-static

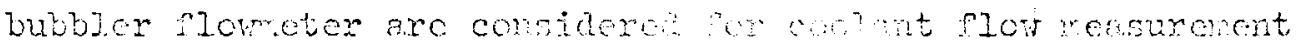

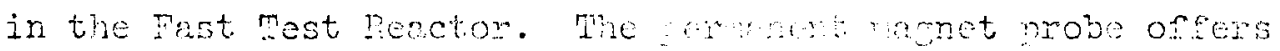
a sonsitivit: on the order of teble on nilivolt ner

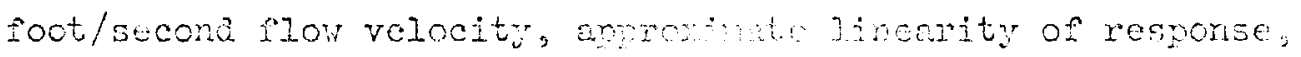

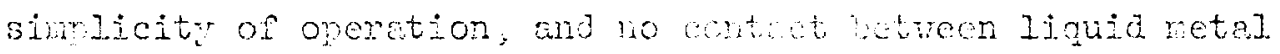
ma electrical insulation. Its ondendity is continent

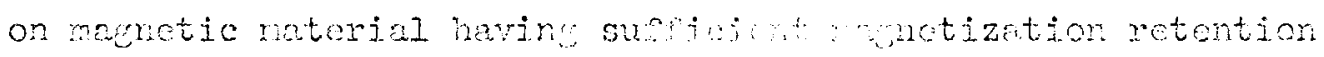

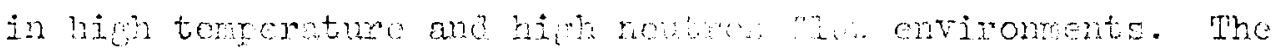

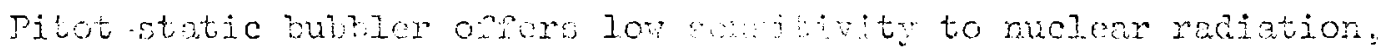
use of of the shelf meterial: we thou ron linear sensi.

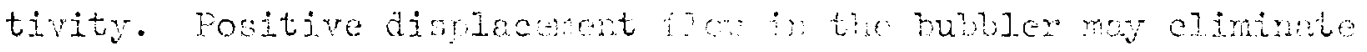

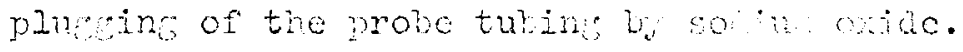


I. Introinction

IT. Pompont inget prote ponden

A. Dening and opention

2.

B. Matrention roded

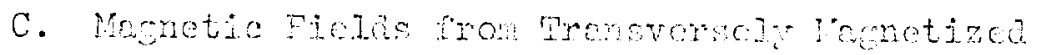
Cyingers

D. Currents and Mende tis the prosenes of plon

7 .

I. Obtainabe senstives

13.

P. We, Jecto wects

16.

c. Conclistons

13.

TIT. Pitot retic mabien lometer

10

Resoremes

2].

Intugnentens

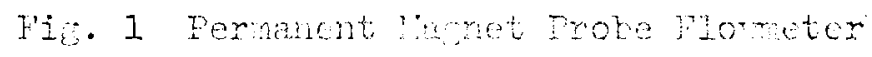

2.

Fig. 2 lathenationl motel ard notetion for

Pemonent ront robe Mometor

4.

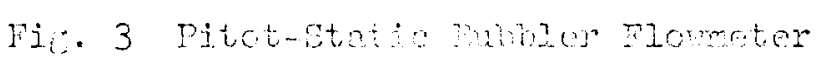

20 . 


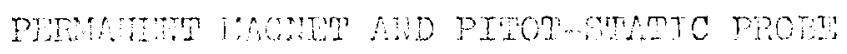

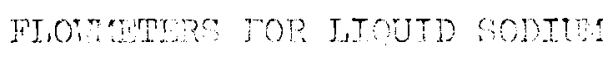

\section{Intronotion}

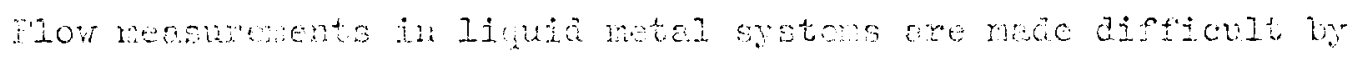

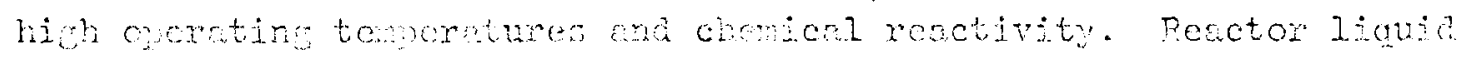

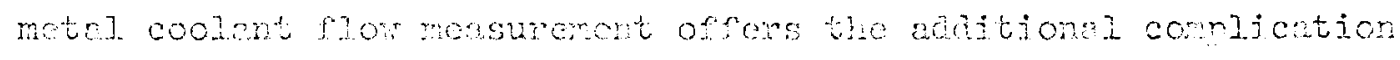

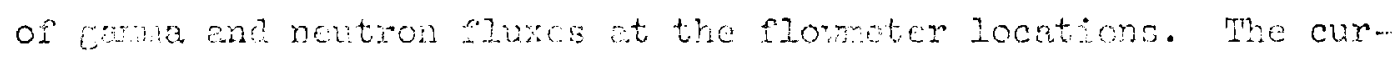

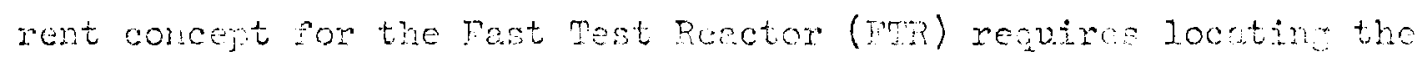

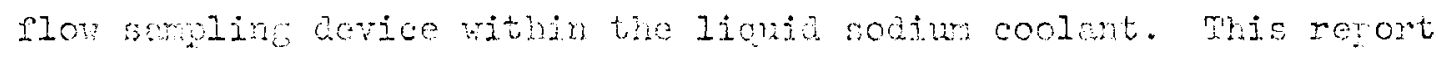
discursos tro yossible ploweter concepts and their cometinility

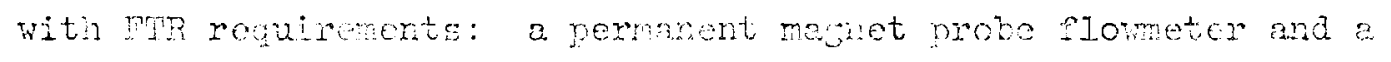
Pirot-btutic derioe.

II. Pemonent Monet probe Mometor

A. Dosicn and preration

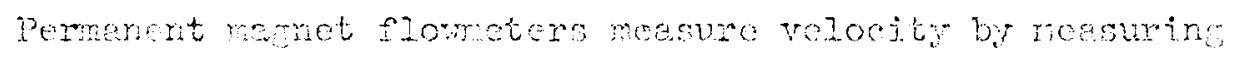
electrichl rotentinl afremed developed betreen tro noints in a

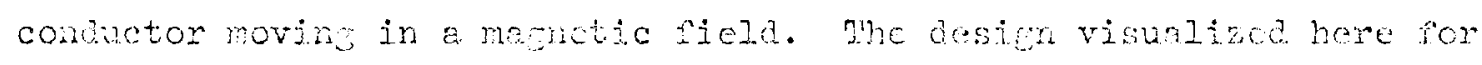

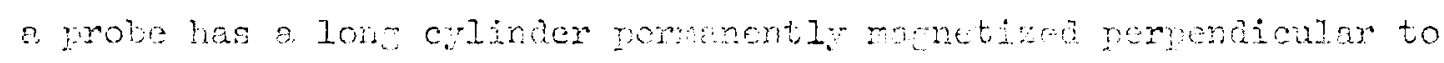

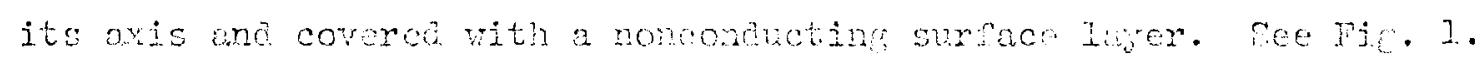

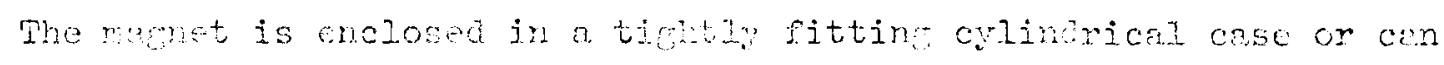

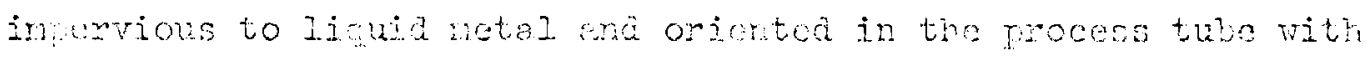

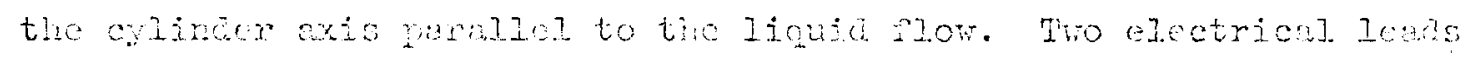

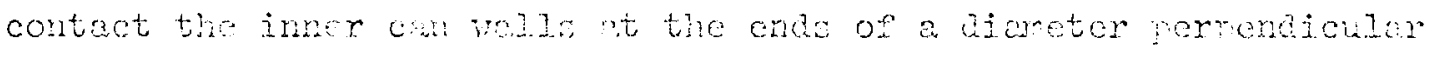

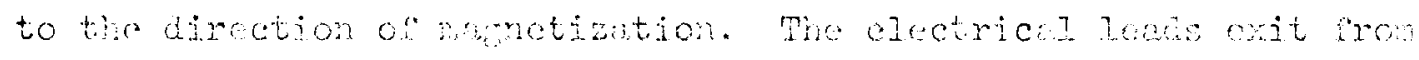

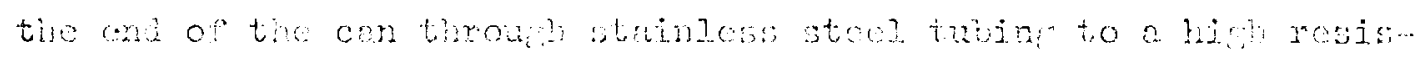

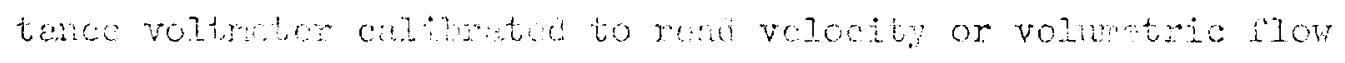

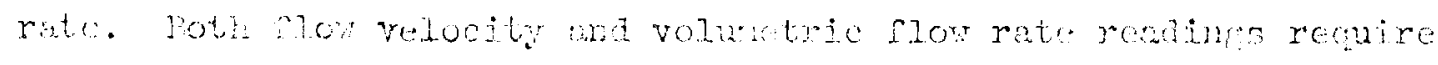

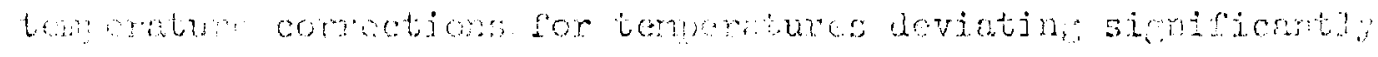



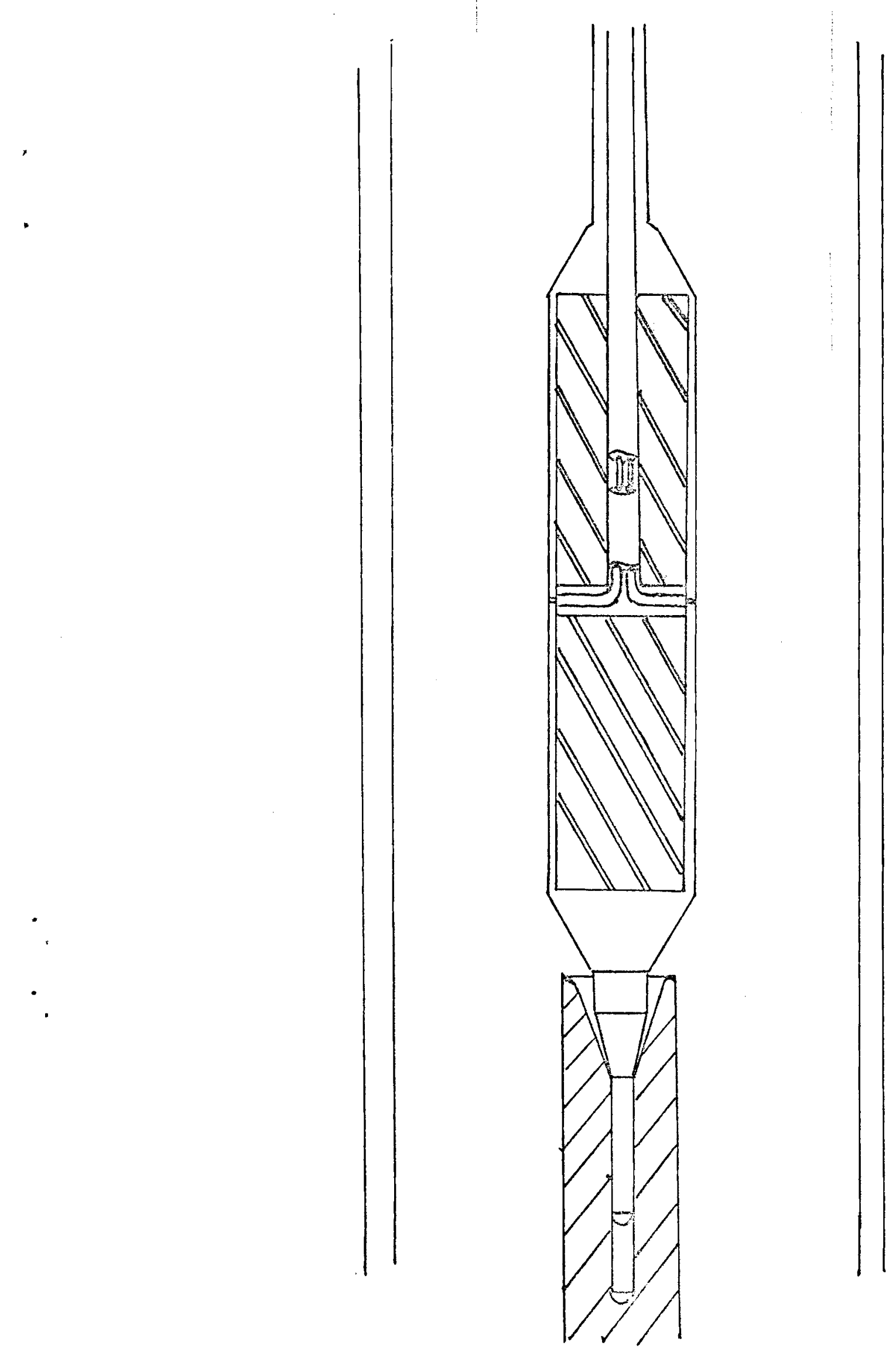


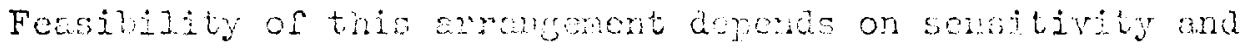
reliability with avoliable neterials. Ve shall hore exmine the

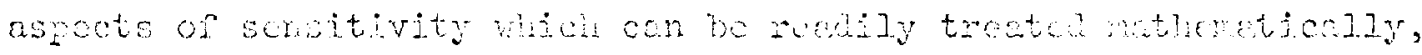
thereby owtoining a sharrer picture of materials roquirenents. B. Methumeicon Model

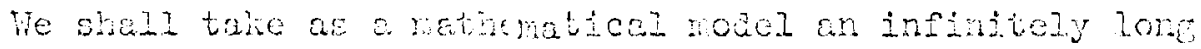

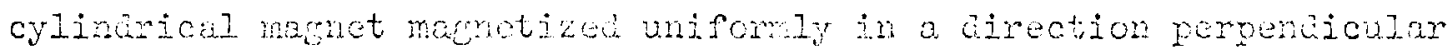
to its axis: The cylink exis is oriented parallel to the plow of an infinite sea of ljovia notgl. The moget of racius $r_{1}$ has a nonconductine laver of nogligivle trichess betrecn it and a closely fitting cled of outer radius $\mathrm{r}_{2}$. See Pig. 2. The cylindrical clad-

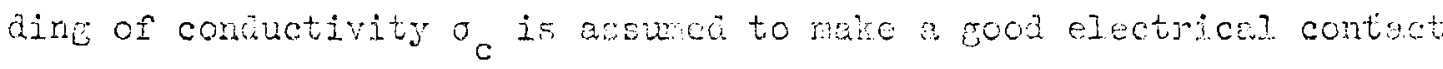
at radius $r_{2}$ vith flomire Jiruid motal of conductivity o. The cladaine

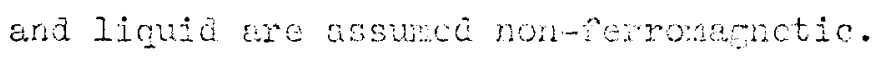

For definiteness wo will take the direction of megretiation as the $x$ axis, the direction of liquid flow (and of the cylinder axis)

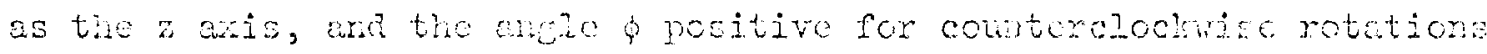

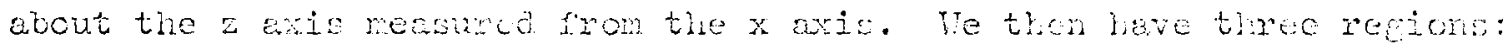

$$
\begin{aligned}
& r<r_{i} \quad \text { Recion I, meglet } \\
& r_{I}<r<r_{e} \quad \text { repion II, clarding } \\
& r>r_{2} \quad \text { Fowion IjJ, liquid metal. }
\end{aligned}
$$




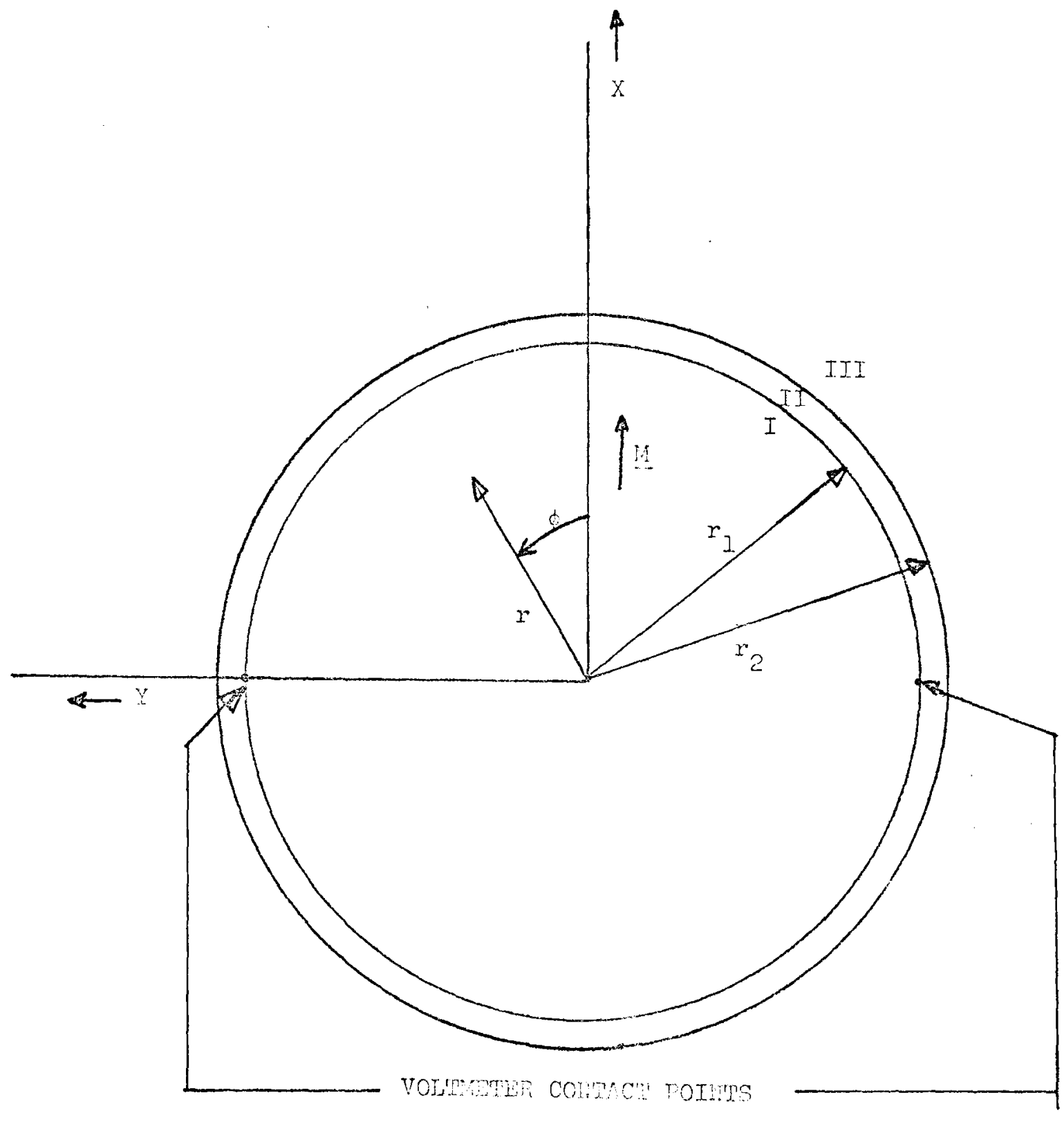

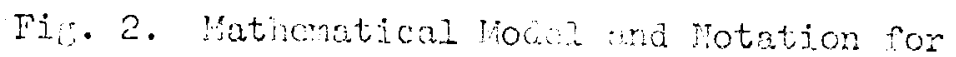
Permancat nonot now plowneter. 
c. Heynetic Fielas from Transvern Maxwelit's equetions for stew and o mon folorizable naterials $\operatorname{arc}$

$$
\begin{aligned}
\varepsilon_{0} \nabla \cdot I & =0 \\
\nabla \cdot B & =0, \\
\nabla \times E & =0, \\
\nabla \times I S & =H_{0}+H_{0} P X:
\end{aligned}
$$

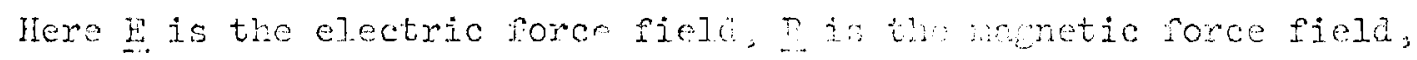

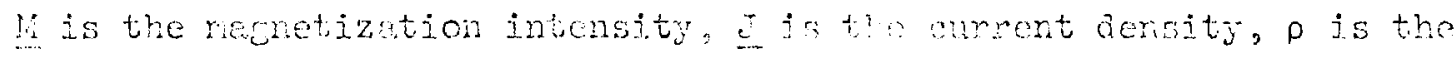
chore density, ard $\varepsilon_{0}$ and $\mu_{0}$ are the witutivity and permeability of reec srace.

For our cylinder unifomly menesten when to the $X$ axis we con trke I inside to be

$$
\underline{B}=\mathrm{I}\left(\mathrm{u}_{\mathrm{p}} \cos (\cdots, i)\right.
$$

where $u_{r}$ and $u_{p}$ are the unit vectom $\rightarrow$ the denections of incressing $r$

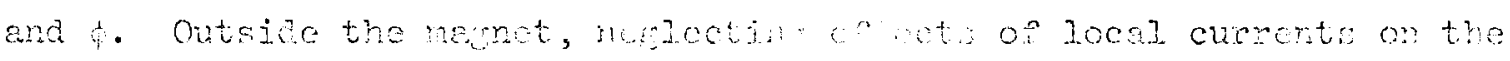

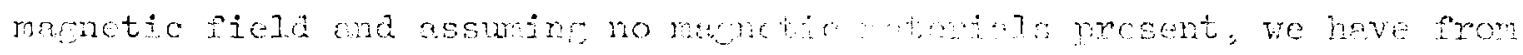
(4)

$$
\nabla \times B=0
$$

and henoe

$$
B=-\nabla \pi,
$$

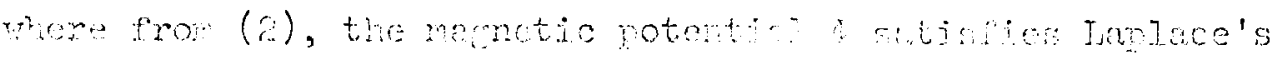
cruction

$$
v^{2}=0
$$




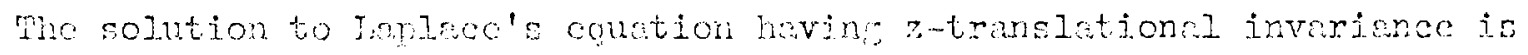

$$
\left.\Phi=\sum_{j=0}^{\infty}\left(\Lambda_{j} r^{j}+C_{j} r^{\cdots j}\right)(j) \cos j \dot{j}+I_{j} \sin j \phi\right)
$$


At the juterfoce at $x_{I}$, $I q$. (2) inplies thet the ralin ccrmonent of I is contimous, whic Io. (h) and the ancence of a surfacc current imly

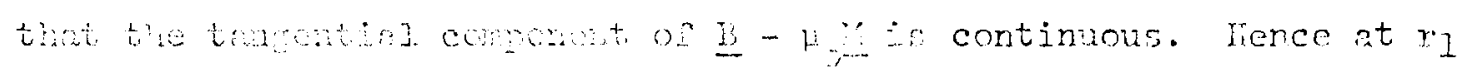
we have

$$
\begin{aligned}
B_{r}=n \cos t=-\left.\frac{\partial \theta}{\partial r}\right|_{r=r_{I}}=-\sum_{j=0}^{\infty}\left(j \hat{n}_{j} I^{j-1}-j C_{j} r^{-j-I}\right)\left(D_{j} \cos j \phi\right) \\
\left.+E_{j} \sin j \phi\right)
\end{aligned}
$$

anct

$$
\begin{aligned}
& \left(2-\mu_{0}\right)_{\zeta}=-\left(B-\mu_{0} y\right) \sin \psi=-\left.\frac{1}{r} \frac{\partial \theta}{\partial \phi}\right|_{r=r_{1}}=
\end{aligned}
$$

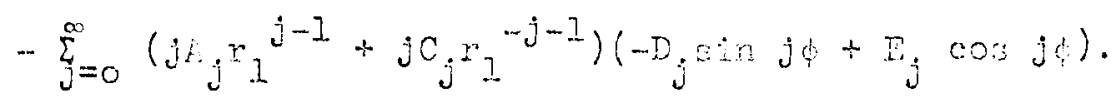

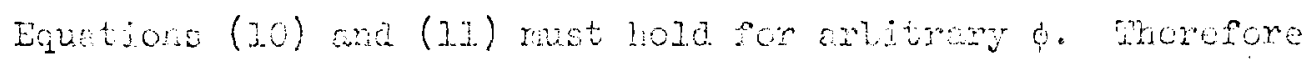

$$
\begin{aligned}
& -A_{1} D_{1}+C_{1} D_{1} D^{-2}=D \\
& H_{1} D_{2}+C_{1} D_{1} P_{1}^{-2}=-\left(D-\mu_{0} D\right)
\end{aligned}
$$

and the other subscriged coerficints con be set to zero. We thus

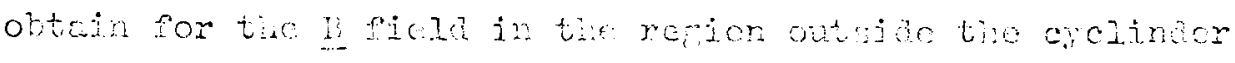

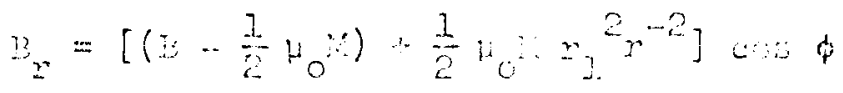

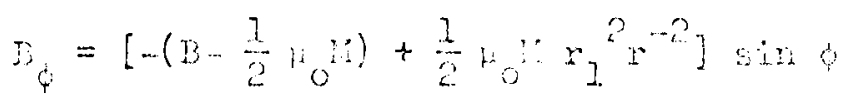


Fote that the 5 and $n$ on the rioht han sing of (1.4) and (25) are the fielas inejie the eytinder. The portion the field in (14)

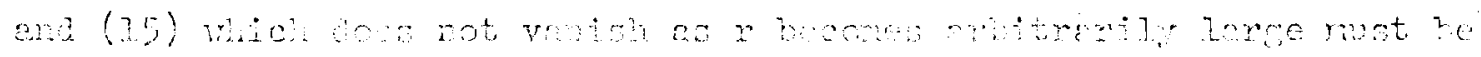

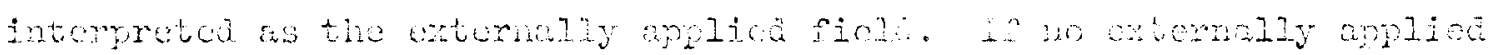

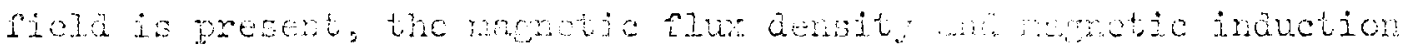

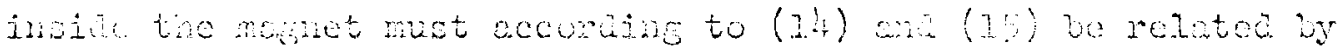

$$
\Sigma=\frac{1}{2} \mu_{0}
$$

on

$$
\mu_{0} H \equiv 3-\mu_{0} H=-3
$$

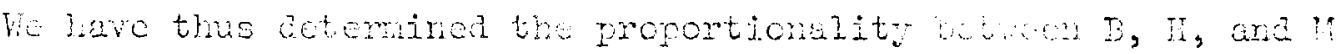

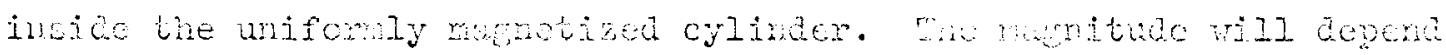

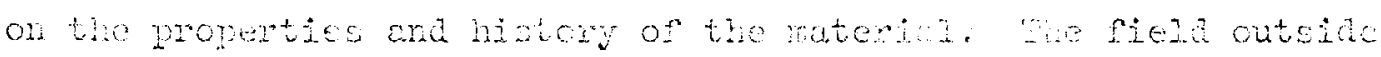

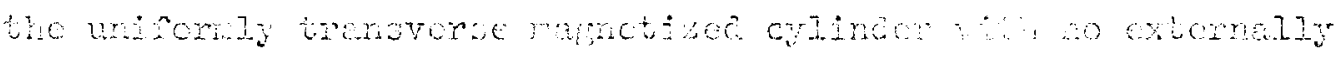
oplies field in acconding to $(2 h)-(17)$

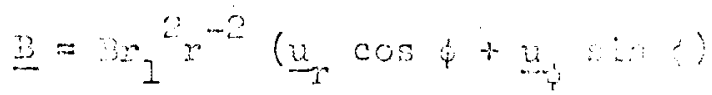

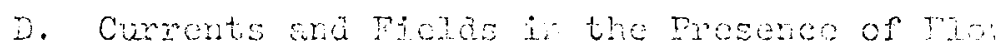

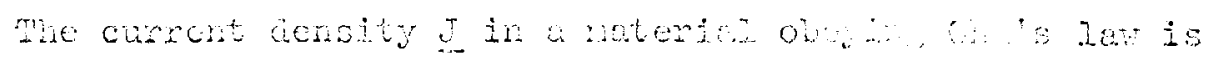

$$
\underline{I}=\sigma(I+\underline{Y} \times \underline{X})
$$

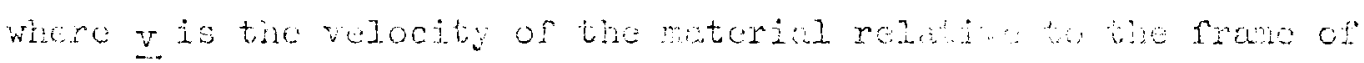

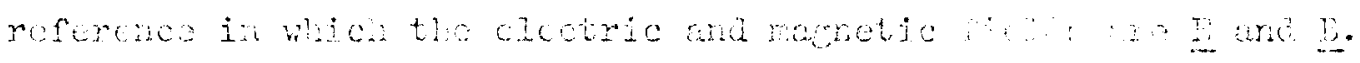

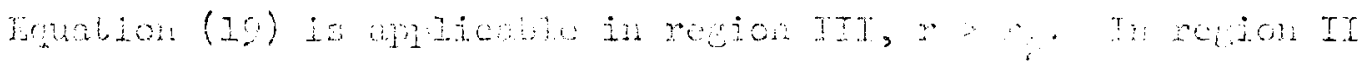
ine nave

$$
J=0 .
$$


whero $\sigma_{c}$ is conductivity of the clading. We assume that the thin insulating layer aoss not allow chure flow into tho menet from its clad. In recrions II ard III, (4) reduces to

$$
\mu_{0} \mathrm{~J}=\nabla \times \underline{B}
$$

and hence

$$
\nabla \cdot I=0
$$

In rejion III, (22) and (IS) say that

$$
\begin{aligned}
\nabla \cdot \underline{E} & =-\nabla \cdot(\underline{v} \times \underline{B}) \\
& =-(\nabla \times \underline{v}) \cdot \underline{B}+\underline{v} \cdot(\nabla \times \underline{B}) \\
& =-(\nabla \times \underline{v}) \cdot \underline{B}+\mu_{0} \underline{V} \cdot \underline{J}
\end{aligned}
$$

For uniforn flow velocity, the curl of $\mathrm{v}$ vanishes. From the symetry of our system, we expoct curront density I to be in the ry plane,

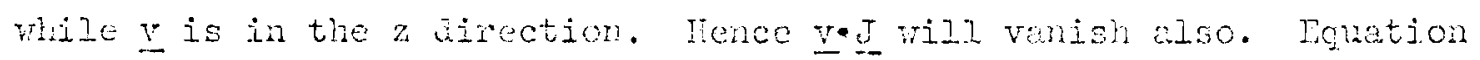
(25) becomes

$$
\nabla \cdot E=0
$$

which is consistent with (1) and ow intuitive ided that tho highly conducting liquid netal siwat not support a froe change donsity in steady otate. Hoto thit mijo (az) holds in regions II and ITI and

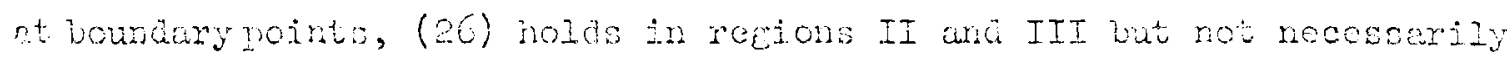
at boundary pointe. Lawados (3) jmplios that in steady state

$$
E-\ldots V
$$

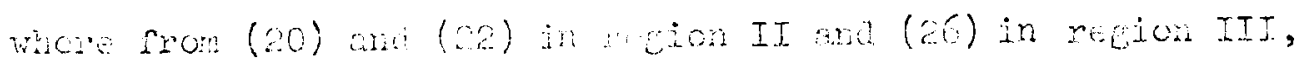

$$
\nabla^{2} v=0
$$


We are thus secking the solution of Laplace's equation (28) which is consiatent with:

$$
\begin{aligned}
& \text { a. } \underline{E}+0 \text { is } r+\infty \\
& \text { b. } J_{r}\left(r_{2} \cdots, \phi\right)=J_{r}\left(r_{2}+, \phi\right) \\
& \text { c. } I_{\phi}\left(r_{2}-, \phi\right)=I_{\phi}\left(r_{2}+, \phi\right) \\
& \text { d. } \int_{r_{1}}^{\infty} J_{\phi} d r=0
\end{aligned}
$$

Relation (32) says that the current does not circle the entire cylinder, so that the net flow through a plane extending radially outward from the inner surface of the cladaing is zero.

The soluticns $V$ to Laplace's equation having invariance with respect to z-translation for regions II and III ve vild. write as

$$
\begin{aligned}
& V_{I I}=\sum_{j=0}^{\infty}\left(F_{j} x^{j}+G_{j} x^{-j}\right)\left(I_{j} \cos i \theta+R_{j} \sin j \phi\right) \\
& V_{I I I}=\sum_{j=0}^{\infty} I_{j} r^{-j}\left(N_{j} \cos j \dot{j}+P_{j} \sin j \phi\right)
\end{aligned}
$$

where ve have alreody imosed $(29)$, but rot yet (30) - (32). The fiela components are, from (27), (33), and (34)

$$
\begin{aligned}
& E_{r}^{I I}=\sum_{j=1}^{\infty} j\left(-m_{j} r^{j-I}+G_{j} r^{-j-I}\right)\left(I, \cos j \dot{q}+K_{j} \sin j \dot{\psi}\right) \\
& E_{r} \operatorname{III}=\sum_{j=1}^{\infty} j L_{j} r^{-j-I}\left(N_{j} \cos j \phi+P_{j} \sin j h\right) \\
& E_{\phi}^{I I}=\sum_{j=l}^{\infty} j\left(\pi j^{j-I}+G_{j} r^{-j-I}\right)\left(I_{j} \sin j \phi \cdots j_{j} \cos j \phi\right) \\
& I_{\psi}{ }^{I I I}=\sum_{j=I}^{\infty} j I_{j} r^{-j-1}\left(i_{j} \sin j \phi-P_{j} \cos j\right)
\end{aligned}
$$


$-10-$

and the currents are from (19) and (20)

$$
\begin{aligned}
& J_{r}^{I I}=\sigma_{c} \sum_{j=I}^{\infty} j\left(-p_{j} x^{j-1}+G_{j} r^{-j-1}\right)\left(I, \cos j h+K_{j} \cos j h\right) \\
& J_{r}^{I I I}=0 \sum_{j=I}^{\infty} j L_{j} r^{-j-I}\left(n_{j} \cos j \phi+P_{j} \sin j \varphi\right)-\sigma v B r_{2}{ }^{2} r^{-2} \sin \phi(40) \\
& J_{\phi}^{I I}=\sigma_{c} \sum_{j=I}^{\infty} j\left(F_{I} r^{j-I}+a_{j} r^{-j-1}\right)\left(I_{j} \quad j i \phi-K_{j} \cos j \phi\right) \\
& J_{\phi}^{I I I}=v \sum_{j=1}^{\infty} j J_{j}{ }^{-j-I}\left(I_{j} \sin j \phi-I_{j} \cos j \psi\right)+o v \sin _{1}{ }^{2} r^{-2} \cos \phi(1+2)
\end{aligned}
$$

We have assumed the magnetic field fro the cylinder is unaltered by the lading and flowing net al. Impost. (30) for arbitrary t requires

$$
\begin{aligned}
& -\sigma_{c} F_{j} I_{j} x^{j-1}+\sigma_{c} C_{j} I_{j} r^{-j-1}-\sigma I_{j} y_{j} a^{-j-1}=0 \quad j=1,2,3, \ldots(4,3)
\end{aligned}
$$

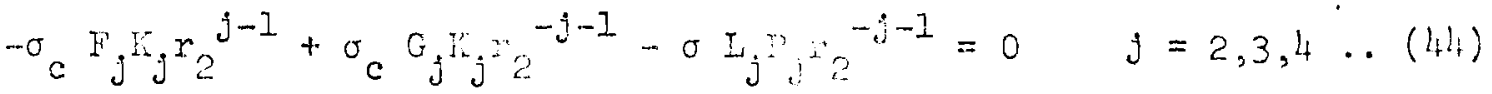

$$
\begin{aligned}
& -\sigma_{C} F_{1} K_{1}+\sigma_{c} G_{1} K_{1} r_{2}^{-2}-\sigma I_{1} D_{2}{ }^{-2}-\sigma_{1}{ }^{2} r_{2}{ }^{-2}
\end{aligned}
$$

Relation (31) for arbitrary $\phi$ requires

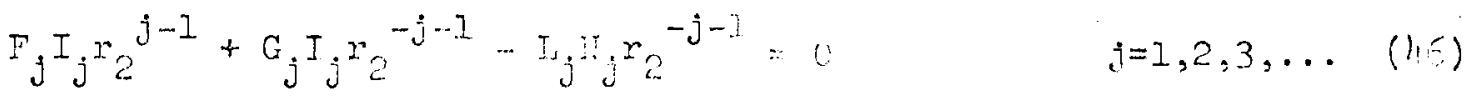

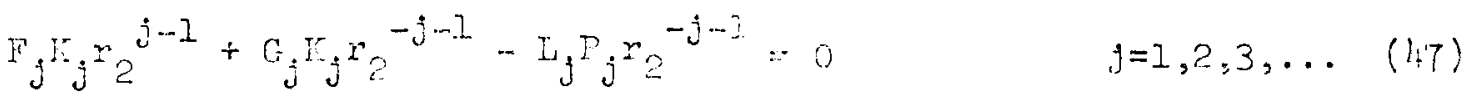

legation (32) is the emo as

$$
\int_{r_{1}}^{r_{2}} J_{4} I J d r+\int_{r_{2}}^{n_{j}} J_{1}^{J r} d r=0
$$

$02^{n}$

$$
\begin{aligned}
& \sigma_{c} \sum_{j=1}^{\alpha}\left(E_{j}\left(x_{2}^{j}-r_{1}^{j}\right)-\sigma_{j}\left(r_{2}^{-j}-r_{1}^{-j}\right)\right)\left(I_{j} \sin j d^{-}-Y_{j} \cos j \phi\right)
\end{aligned}
$$

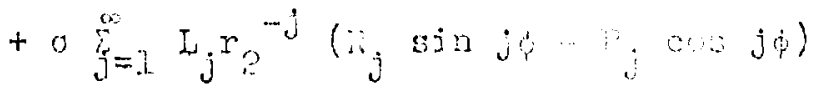


For this to be true for arbitraxy $\&$, ne lans

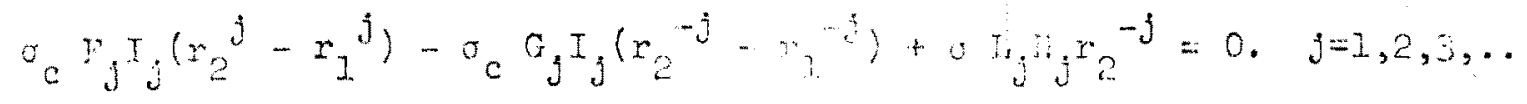

$$
\begin{aligned}
& -\sigma_{c} P_{j} K_{j}\left(r_{2}^{j}-r_{1}^{j}\right)+\sigma_{c} G_{j} r_{j}\left(r_{2}{ }^{j} \ldots z^{-j}\right)-o_{j} P_{j} r^{-j}=0 \quad j=2,3, \ldots
\end{aligned}
$$

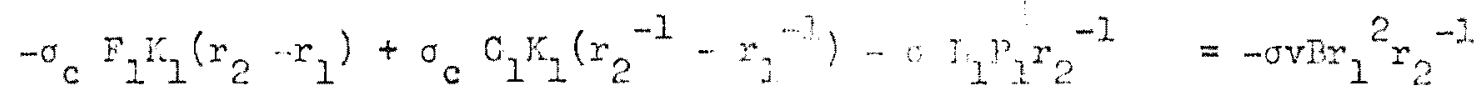

We now solve the set $(43)-(1,7)$ a. (50) - (52) for the

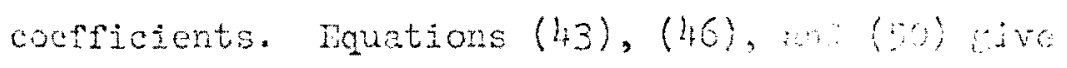

$$
\begin{aligned}
& F_{j} I_{j}=0 \\
& G_{j} I_{j}=0 \\
& I_{j} L_{j}=0 .
\end{aligned}
$$

Manons $(44),(47)$, ane (51) cive

$$
\begin{aligned}
& F_{j} K_{j}=0 \\
& G_{j} K_{j}=0 \\
& L_{j} P_{j}=0 .
\end{aligned}
$$

Echations $(1+5),(52)$, and $(17)$ for $j=7$ ar an voncro conficiento of interest:

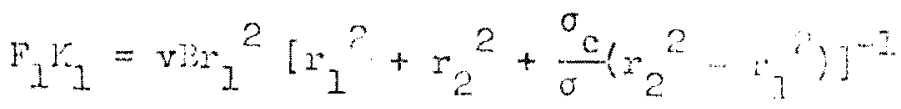

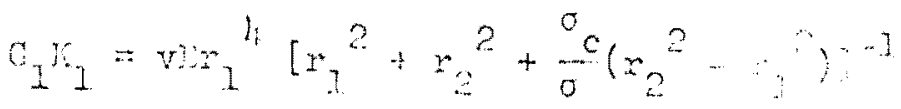

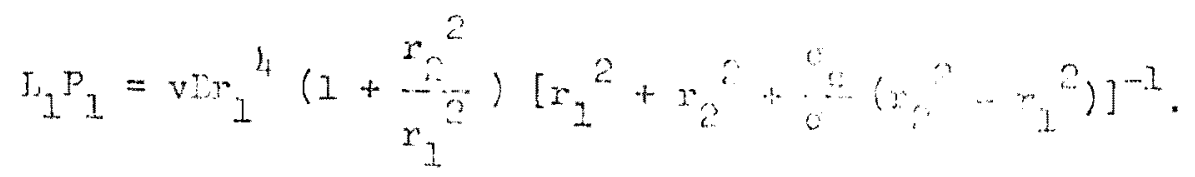


The electric fielas $(35)-(38)$ are we meificaly:

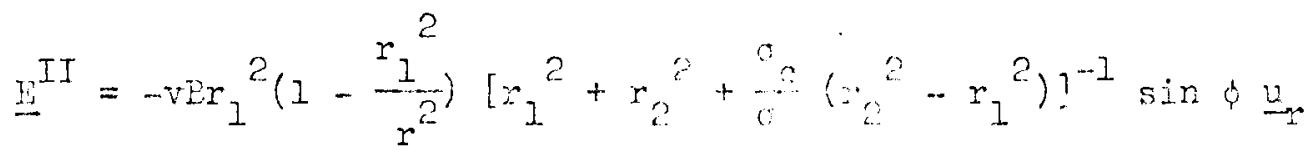

$$
\begin{aligned}
& -\operatorname{vDr}_{1}^{2}\left(z+\frac{r_{1}^{2}}{r^{2}}\right)\left[r_{1}^{2}+r_{2}^{2}+0\left(a-r_{1}^{2}\right)\right]^{-1} \cos \phi u_{\phi} \\
& \underline{E}^{T I T}=\operatorname{vJr}{ }^{4} r^{-2}\left(1+\frac{r_{2}^{2}}{r_{1}}\right)\left[r_{1}^{2}+r^{2}+\cdots\left(r_{2}^{2}-r_{1}^{2}\right)\right]^{-1} \sin \phi u_{r} \\
& -\operatorname{vir} r_{1}^{4} r^{-2}\left(1+\frac{r_{2}^{2}}{r_{1}{ }^{2}}\left[r_{1}^{2}+r_{r}^{2}+\frac{\sigma}{\sigma}\left(r_{2}^{2}-r_{1}^{2}\right)\right]^{-1} \cos \phi u_{\phi}\right.
\end{aligned}
$$

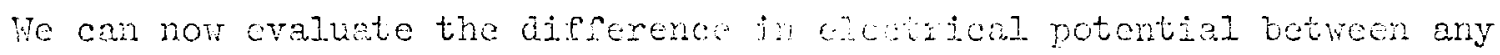

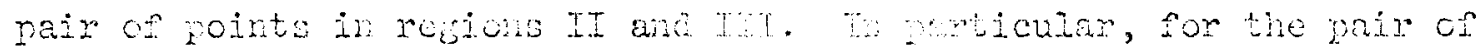

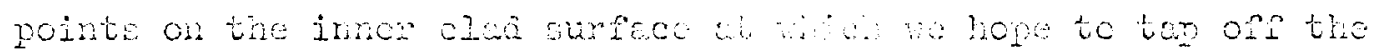

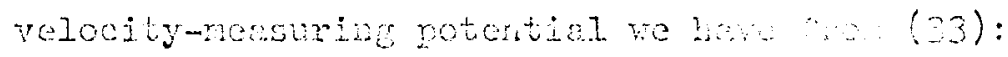

$$
V\left(r_{1}, \frac{\pi}{2}\right)-V\left(r_{1},-\frac{\pi}{2}\right)=4 \operatorname{VDr}_{1}^{3}\left[r_{1} \div x_{2}^{2}+\frac{\sigma}{0}\left(r_{2}^{2}-r_{1}^{2}\right)\right]^{-1} .
$$

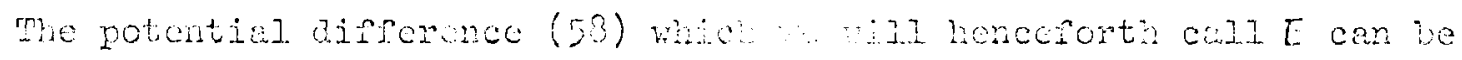

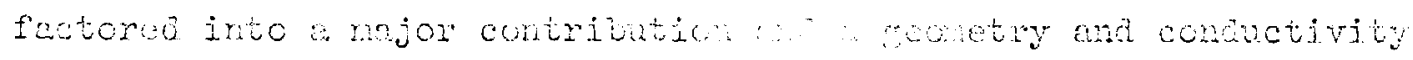
depondent conrection:

$$
E=2 v r_{1}{ }_{1}
$$

where

$$
\left.r_{1}=2\left[1+\left(\frac{r_{2}}{r_{1}}\right)^{2}+\frac{\sigma_{c}}{\sigma}\left(\frac{r_{1}}{r_{2}}\right) \cdot \ldots \cdot\right)\right]^{-1}
$$


Whe potential differonce giver by $(59)$ and $(60)$ is the potential difference across the teminals of a high resistance voltmeter having low resistance leads maling cood contoct witl the inner can ralls.

To evaluate the effects of leakage vetween clad and naspet, a differcnt icealization is useful. For gool electrical contact betwecn the marretized cylindor of conductivity $\sigma_{\text {n }}$ oncitu clat, the potchtial difference across the inner clad surfaces is found to be

$$
E=2 \cdot \operatorname{Vir} r_{1} r_{2}
$$

where

$$
I_{2}=2\left[\left(1+\frac{\sigma_{m}}{\sigma}\right)\left(1+\left(\frac{r_{2}}{r_{1}^{2}}\right)+\left(\frac{\sigma_{c}}{\sigma}+\frac{\sigma_{m}}{\sigma_{c}}\right)\left(\left(\frac{r_{2}}{r_{1}}\right)^{2}-1\right)\right]^{-1} .\right.
$$

This 7 attor comertion $(G 2)$ reduces to the one for a machet insulated fron its clad in the linit $o_{\mathrm{m}} \rightarrow 0$.

i. Obtainable Sonsitivity

Whe voltage expected across the voltmeter teminels is

$$
E=2 V T H K
$$

where $\mathrm{K}_{\mathrm{s}}$ is a poduct of conpection fuctors, incluaing $\mathrm{K}_{\mathrm{I}}$ or $\mathrm{K}_{2}$ as previonsy aiscuased. The saturation montization of Alnico VII. in an cxternel mageide field and subsegut renovel of the applied

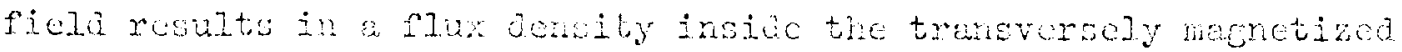
ylinder of (1)

$$
13:=.13 \text { rober } / m^{2} .
$$

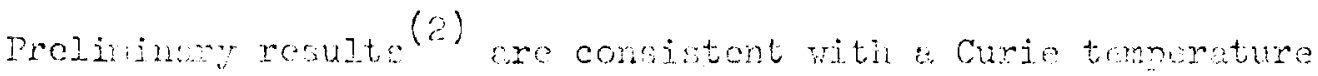

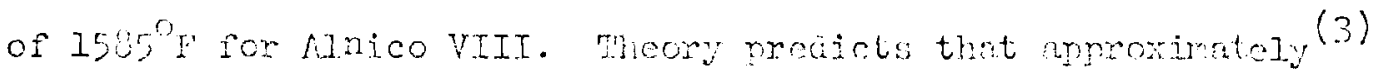

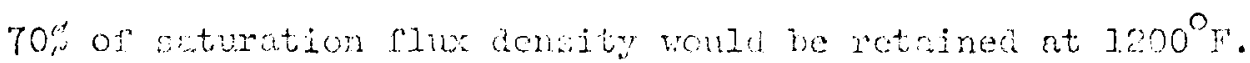

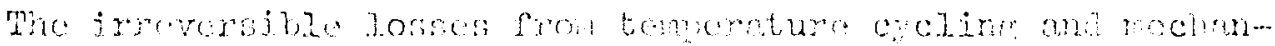


we nimht hope to retain $50 \%$ of the $70 \%$ thome saturation value, or Eprroximotely

$$
B=.065 \text { waber } / 22^{2}
$$

Por a 1 inch dianeter magnetic cylinter, wr toding corrections, we obtain a semsitivity

$$
\begin{aligned}
& \frac{E}{v}=2\left(.065 \text { weber } / \mathrm{m}^{2}\right)\left(.3 \text { and } \times 2.54 \times 10^{-2} \mathrm{~m} / \mathrm{inch}\right) \\
& =1.65 \text { millivolt } /(\text { mations } 1000)
\end{aligned}
$$

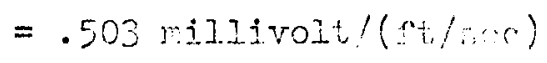

on, in tems of volumetric flow rate $\dot{i}$,

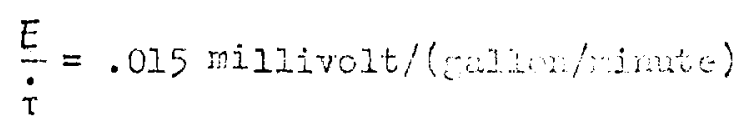

In the current IrR process tube desin.

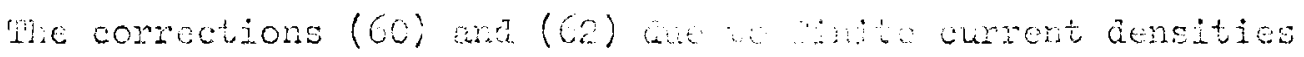

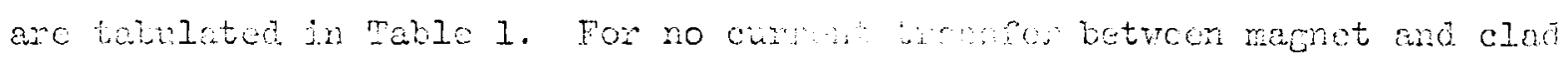

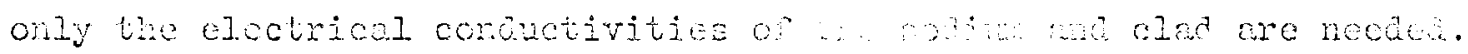

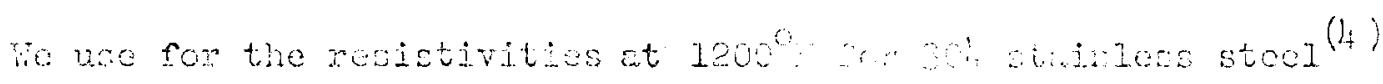

$$
p_{c}=\frac{1}{\sigma_{c}}=123 \cdot \min 2 \cdots
$$

and for sodiun (5)

$$
p=\frac{1}{0}=35.6895 \mathrm{row} \text {. }
$$

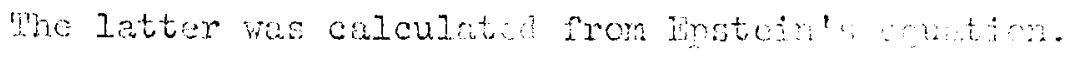

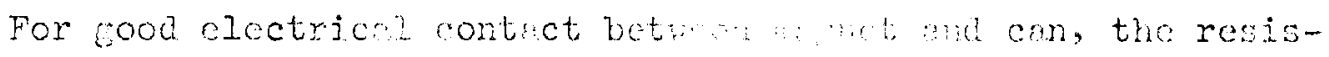
tivity or conductivity of the nugnetse w. 
Cood values of resistivity of $\Lambda$ lnico VIII were not readily available, so $K_{2}$ was tabulated for two values of marnet resistivity:

$$
\begin{aligned}
& \rho_{m}=\frac{1}{\sigma_{m}}=50.0 \text { micro-ohm cm } \\
& \rho_{m}=\frac{1}{\sigma_{m}}=314.34 \text { micro-ohm cm. }
\end{aligned}
$$

The first of these mannet resistivitics ${ }^{(1)}$ is that of Alnico VIII at $25^{\circ} \mathrm{C}$; the second is obtained by assumine a linear temperature coefficient of resistivity that is approximately that obtained by averagine those of the components with rass fraction reichting.

From the table we conclude that a thin clad is preferable and that electrical insulation between machet and clad is helpful but not essential. The difference between the correction factors $K_{I}$ and $K_{2}$, does show the necessity of having tho type of electrical contact between floweter and clad remain unchenged durin operation.

\section{TABLE 1 .}

Finite Current Density Correction Factors

$\begin{array}{cccc}\left(\mathrm{r}_{2} / \mathrm{r}_{1}\right) & \mathrm{K}_{1} & \mathrm{~K}_{2}\left(\rho_{\mathrm{m}}=50 \mathrm{micro-ohm} \mathrm{cm}\right) \mathrm{K}_{2}\left(p_{\mathrm{m}}=31 . .34 \text { microm on cy }\right) \\ 1.00 & 1.00 & .584 & .898 \\ 1.06 & .925 & .505 & .817 \\ 1.08 & .901 & .483 & .792 \\ 1.10 & .879 & .462 & .768 \\ 1.20 & .776 & .376 & .664 \\ 1.30 & .688 & .313 & .578\end{array}$


The development presented here has assurned a uniform sodium velocity outside the cylindrical magnet claddine. There will actually be a velocity profile with low velocity boundary lavers adjacent to surfaces. The order of the refects of non-unfform velocity can bo estinated roundy by the follovine iacalization.

The boludary layer of sodiun outside the clad will be considered as hevine a zero velocity. Its effects are then mathomatically similar to those of the cladding can. We can replace the can thickness $r_{2}-r_{1}$ by a value $r_{2}^{\prime}-r_{1}$ where $r_{2}^{\prime}-r_{2}$ is the boundary laver thichness, and we simultaneously replace the can conductivity $\sigma_{c}$ by some effective value $\sigma_{c}^{\prime}$ ketween can and sodium conductivity. For the extreme case of a clad of nerlibible thickness, we take $\sigma_{c}{ }^{\prime}=\sigma$ (sodium conductivity) to obtain from (60)

$$
r_{1}, \approx\left(\frac{r_{1}}{r_{2}}\right)^{2} .
$$

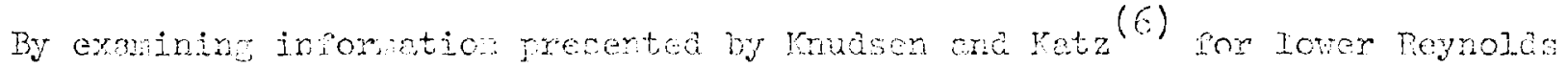

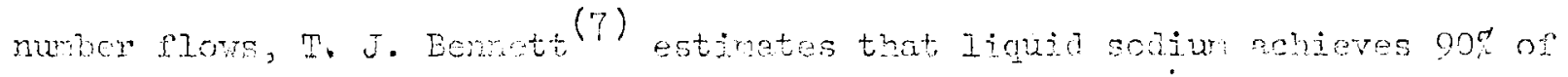
a mean $17.2 \mathrm{ft} / \mathrm{sec}$ flov volocity in an annulas recion with 1. " ID ond 3.75" OD outsiae an innem boundary layer of less than .065" thickness. The corresnonting correction is

$$
K_{1}^{\prime}=.783
$$

The choice of the $90 \%$ of mean slow rate as detomining the boundar. was arbitrary and conservetic. It sems reaconable to exrect to multinly the correction (60) or (62) for can conductivity by a bourdary correction factor o order $\left(r_{2} / r_{2}{ }^{\prime}\right)^{2}$, the jatter factor on the order of $30 \%$ but somant velocity denendent, since boundar. layer thickness devends on volocity.

F. Nerlected Rrfecti

Amore the offects neilected in this treatment are 
:

1. Finite lencth effects on the nametic field.

2. Finite length current shinting; effects.

3. Finite sodiun flow-aree encets.

4. Effects of external ferrometic materials.

5. Poor electrical contact ofocts between sodium and probe clad.

6. Effect of eddy currente on the manctic fiela.

The finite lencth effects on tire monejo field and the current shunting effects around the end of the rinte length cylindrical probe are difrirult to ascoss. It scems masible, however, that these effects are of the sane orden as in the flow-through permanent manet flometer and hence that the become omal for lenth to dianeter ratios in excess of 4 . It scches csential to detemine these effects cxperimentally.

An estimate of the effect of the indte wea of the sodium flow rather thon an infinite ses soo mblemically tractable and will be attempted in further studics of the rrobe flometer. Te anticinate that the relative correction bill be on the order of the square of the ratio of nacnet diancter to ina inside disneter, since the Is field outside the cylinder hes on $2^{-2}$ devendence.

The effects of exterial ferromente weturals wjll be difricult to incluae, but if the effect on the finte orea of sodium flow proves to be small, the effects ortemal $B$ rields in the

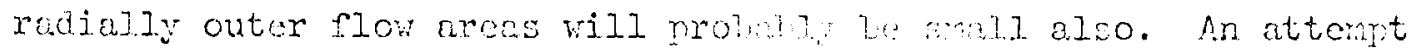


will be made to estimate the effect on calibration of removal or rcorientation of the macnet fror adjacent instrument nrobe tubes. The effects of noor elcotrical contact between can and sodium due to incomplete surface retting or formation of oxide or bubble layers should not dirfer sienificantly in nature or size from corresponding efrects in flow-throurh flowneters.

The effects of eddy currents on the magnetic field are described qualitatively as sweening of the $B$ field domstrean. This effect becomes sicnificant in flow through flometers only for large diameters, 5 inches or more.

G. Conclusions

The probe type permanent macnet flowmeter appears camable of yielding the desired sensitivity if the macretic meteriols retain surficient marretization in neutron fluxes and temeratures characteristic of the reactor enviroment. Response is neerly lineer with flow velooitr, norlinearities apoerine becuse of velocity derendence of bounary layer and eddy current. Temperature correction, primanizy because of toremeture derendence of the marnetization, will be necessary. A major advartare of the permancht narnet nrobe envisioned hore is that eleotical louds nover contact molter sodium, and honce insubation necd be canable of withstanding only hich temperature and not comosive on rettine action. 
III. Pitot-static Bubler Flometer

Jubline positive dis lecement flowe of aron cover gas inwer through conventional Pitot-static probes may eliminate pluming of the probe tubing by sodium oride precinitent. Ammuar pitot and static ports milled into the upstrew and downtrem feces of a aisc probe transverse to the flow (as in

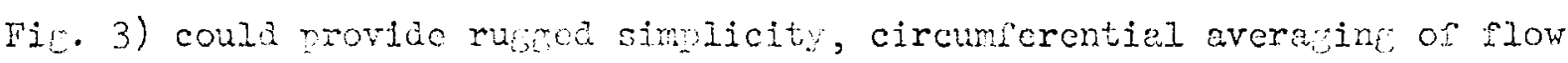
irrecularitics, end resnonse smmetry under flow reversal conditions.

Key acvantoges of the pitot-mstatic bubbler flometer include low sensitivity to nuclear radiation exposure, use of of the-shelf materials and auriziatics, and hich rosponse sencitivity. For Fast Test Reactor design conditions $\left(550\right.$ em licuid sodiun, specific crovity 0.793 at $1200^{\circ} \mathrm{p}$, Ploring thr ugh J" ID by 3.75" OD amulus pierced by $0.5^{\prime \prime}$ OD cas-sangle tube), the Pitot-static jassure dironenting given by Dernoulli's

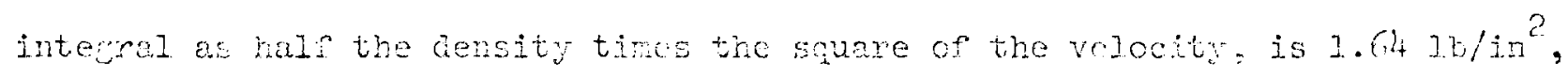
lare enoun to be ecsily mecurable vith cood medsion.

Twin positive displacement rotery vane rums on one ariveshopt should

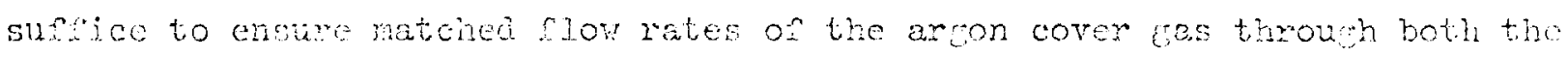
Pitct and static tubas, so that the anomic pressure aron throukh each ture does not disturb the presoure aifforential. Tut the strons variation of

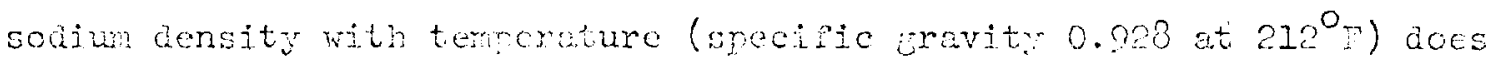
ingly the need for tomenature-devendent calibration of the flometer over the operating rane. 


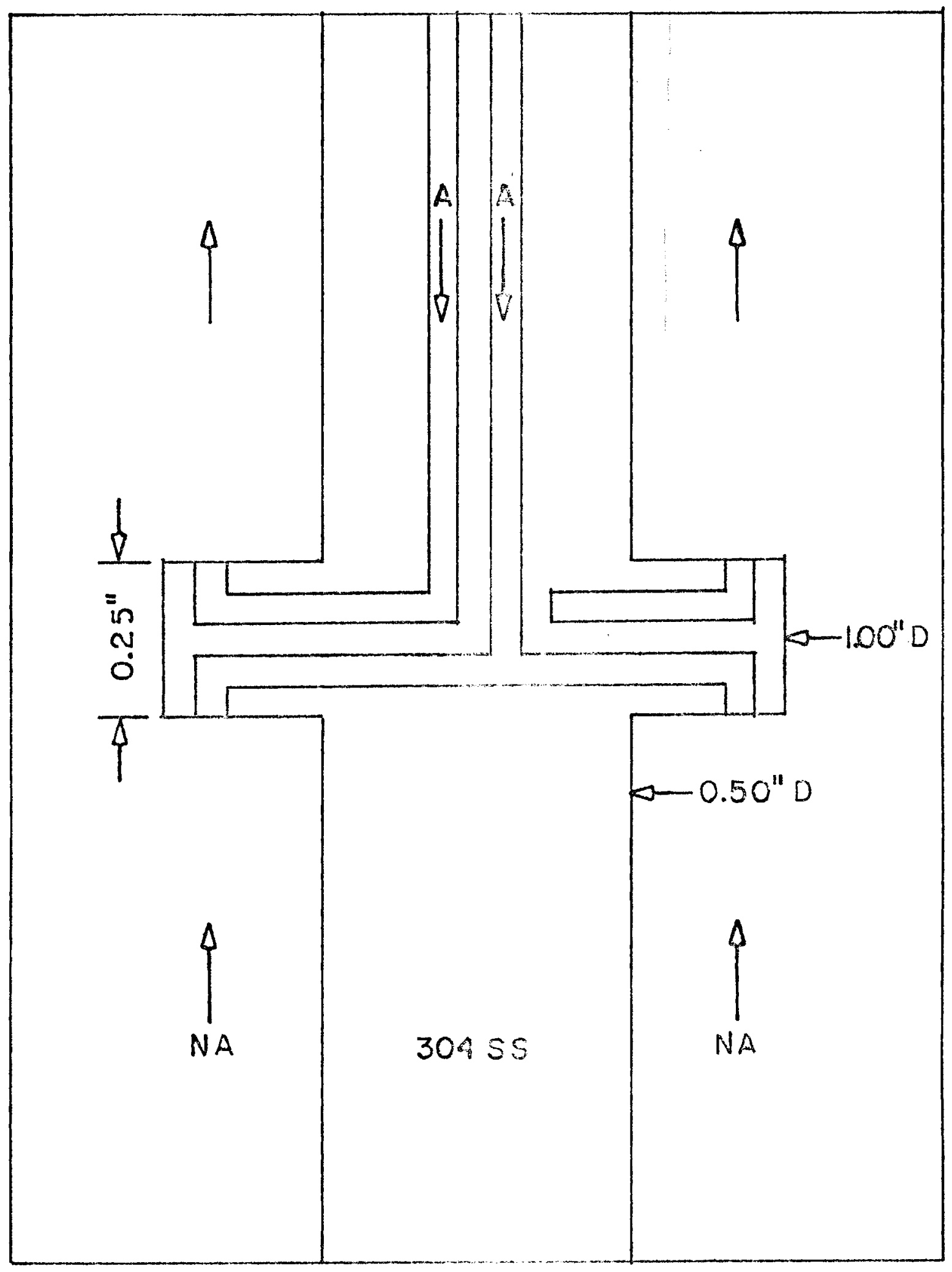

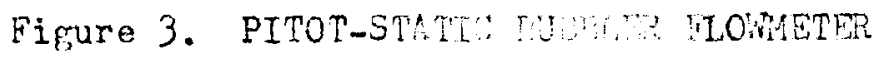


RTFIMIOSS

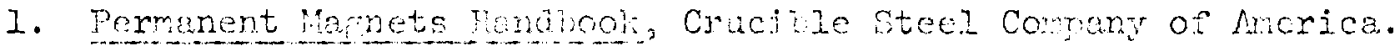

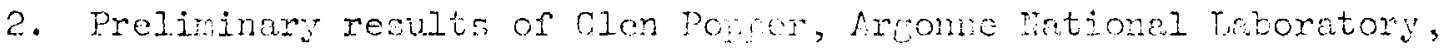

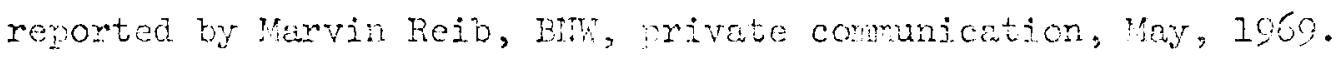

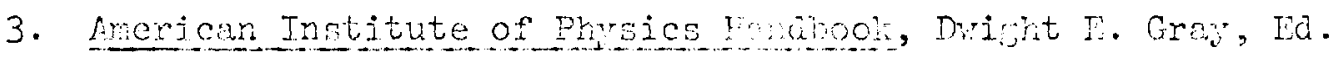
MeGrak-Hill Book Co., Inc., Wry York, 1057 .

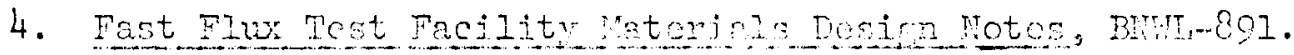

5. Licuid Metels llandbook, TID-127, :1. 29, July, 1955.

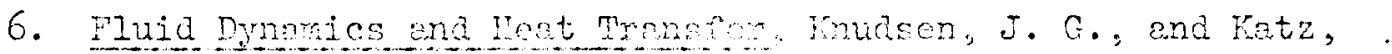
Donald I., Ifocrew-Ii]], 1958.

7. T. J. Dennett, privete conunisetons, lay 12, 1069. 
9 U.S. Atomic Fnergy Conmission Division of Reactor Dev \& l'tech

Asst Jirector for Project Mgrit., A Giambusso

Frlir Project office, JJ Morabito

Asst Director for Plant Engineering, (3) MA Rosen, R Feit, E Wenzinger

Asst Director for Engineering Stanciards, JW Crawford

Asst Director for Reactor Enginecring (2), EE Kintner, NE Todrias

Asst Director for Reactor Technolocy, EE Sinclajr

Asst Director for Nuclear Safety, AJ Pressesky

$1 \quad$ AEC Richland Orerations office

FFTF Program

JM Shivley

$3 \quad$ AEC Site Renresentatives - BNW

PG Holsted

3 Argonne National Laboratory

RA Jaross

1 IMPBR Promam Office

2 Liquid Metal Information Center

JJ Droher

2 Westinghouse Electric Comporation

TCR Kelley

RS Strzelecri (Richland)

42 BNH/Prir On Eite

\begin{tabular}{|c|c|}
\hline ER Astiey & AG Gibbs \\
\hline So Arneson & FC Gronemeyer \\
\hline RL Brown & Je Hauth \\
\hline CP Cabell & PI」 Iofmann \\
\hline JC Cochran & DL rottwitz \\
\hline DI Condotta & DI, Jesser \\
\hline RR Cone & CW Lindenmeier \\
\hline Gil Davison & WB MeDonild \\
\hline BHA Duane: & JS liciahon \\
\hline Fn jivans & JJ Regimbaz \\
\hline LE Fort & Ho Rieb (5) \\
\hline
\end{tabular}

RE Schenter

RJ Squires

KB Stewart

RJ Squires

CD Swanson

MR Wood

Fiprip Files (2)

Tech Files (5)

Tech Pubs (2) 